\title{
Grey Evaluation Model Based on Reformative Triangular Whitenization Weight Function and Its Application in Water Rights Allocation System
}

\author{
L.N. Zhang ${ }^{*}$, F.P. Wu and P. Jia
}

Business School of Hohai University, Nanjing, 210098, P.R. China

\begin{abstract}
In the actual analysis of grey clustering evaluation, the length of a grey clustering interval was partially longer, which is determined by the grey clustering evaluation method based on the center-point triangular whitenization weight function. In response to problems like this, this paper proposes a new grey evaluation method on the basis of the reformative triangular whitenization weight function. Motivated by ideas of the end-point and the center-point triangular whitenization weight functions, we construct a new compact-center-point triangular whitenization weight function. Then, several aspects of the three kinds of triangular whitenization weight functions are compared, such as the crossing properties of grey cluster, clustering coefficients, rules for grey clustering interval, rules for choosing end-points and clustering performance. In the following, this paper proposes an example about the evaluation of a basin initial water rights allocation scheme, which analyzes the three methods to further verify that the new grey clustering evaluation method is feasible and effective. The results indicate that the compact-center-point triangular whitenization weight function precedes the end-point triangular whitenization weight function and the center-point triangular whitenization weight function soundly.
\end{abstract}

Keywords: Clustering coefficients, grey clustering evaluation, grey system theory, evaluation model, initial water rights allocation, triangular whitenization weight function.

\section{INTRODUCTION}

In cybernetics theory, we always use the intensity of the color to describe the degree of clearness of the information. For instance, Ashby called an object with unknown internal information as "black box". And the citizens put forward that there should be an increase in the transparency of the political information on the basis of the wish of understanding the decision and its forming process of the policy. Hence, we can use "black" to express unknown information, use "white" to indicate completely known information, and use "grey" to represent partially known information $[1,2]$. Grey system theory is a method which is widely applied in studying the analysis of systems with small sample and incomplete information [3-5]. Grey clustering evaluation method is part of the grey system theory, which is suitable for evaluating objects with partial information. The key point of the grey clustering evaluation method is to construct whitenization weight function. We can dredge up underlying information to evaluate the object based on the whitenization weight function. Whitenization weight function refers to the preference for different values of a grey variable within its scope. So, constructing whitenization weight function is the key step to solve this problem.

Liu and Zhu proposed the grey clustering evaluation method based on the end-point triangular whitenization

*Address correspondence to this author at the Business School of Hohai University, Nanjing, 210098, P.R. China; Tel: 025-58099312;

Fax: 025-86902496; E-mail: linazhangv@163.com weight function (abbreviated as ETWF) [6]. As an important branch of constructing whitenization weight function method, ETWF is an effective method to indicate the preference of the grey variable within its scope for different values. This method is widely used in the fields of evaluation research, such as regional leading industry, regional comprehensive strength of science and technology, web sites [7-9]. And some researchers also integrate this method with other methods to evaluate the agricultural ecological environmental quality, the investment of venture capital, the water eutrophication degree of wetland, traffic safety and the construction of road system, self-propelled gun, the information functional requirements [10-16]. Besides, Liu and Xie did further research on the theory of ETWF, proposed the grey clustering evaluation method based on the center-point triangular whitenization weight function (abbreviated as CTWF), and proved that CTWF precedes ETWF in several aspects, such as the crossing properties of a grey cluster, clustering coefficients and rules for choosing end-points [17].

Thus, we can see that the research on the grey evaluation method based on the triangular whitenization weight function is still in a developing stage at present [18]. Compared to less theoretical research, the existing achievements concentrated mainly on the aspects of the application. There are still some areas which are needed to be improved theoretically [17]. Based on the pre-research and pre-analysis for the theory of CTWF, we figure out the problem of which the division of the grey clustering interval of triangular whitenization weight function is lack of certain 
scientific ideals, then we take it as a breakthrough point to conduct research (see Section 3.3.). Hence we construct the triangular whitenization weight function based on the compact-center-point, and analyze it by comparing it with ETWF and CTWF.

The remainder of the paper is organized as follows: In Section 2, we propose the grey clustering evaluation method based on the compact-center-point triangular whitenization weight function (abbreviated as CCTWF). In Section 3, several aspects of the three kinds of triangular whitenization weight functions are compared, such as the crossing properties of grey cluster, clustering coefficients, rules for grey clustering interval, rules for choosing end-points and clustering performance. In Section 4, we give an illustrative example to verify the grey clustering evaluation method based on CCTWF and to demonstrate its validity and feasibility. In Section 5, we finish this paper with some conclusions.

\section{GREY EVALUATION MODEL}

Motivated by the ideas of the grey clustering evaluation methods based on ETWF and CTWF [8, 17], the grey clustering evaluation method based on CCTWF is introduced in this paper. And we conduct further research by taking the problem of which the division of grey clustering interval of triangular whitenization weight function is lack of certain scientific ideals as the breakthrough point. Based on the research of the properties, such as the crossing properties of a grey cluster, clustering coefficients, rules for grey clustering interval, rules for choosing end-points and clustering performance, this paper improves the existing triangular whitenization weight function and establishes CCTWF. The calculation procedure of the grey clustering evaluation method based on CCTWF is as follows:

Assuming that $O=\left\{O_{i} \mid i=1,2, \ldots, n\right\}$ is the object set which is clustered into different grey clusters of $s$, $s \in\{1,2,3,4\}$, corresponding to the poor, general, good and excellent types respectively. And $g=\left\{g_{j} \mid j=1,2, \ldots, m_{i}\right\}$ is the evaluation index set of an object $O_{i}$. $x_{i j}, i=1,2, \ldots, n ; j=1,2, \ldots, m_{i}$ are the observation values of an object $O_{i}$ for clustering index $g_{j}$. We can evaluate the corresponding object $O_{i}$ according to the observation value $x_{i j}$. In order to describe it properly, we take any object $O_{i} \in O$ as an example. The procedure is as follows:

Step 1: Determine the $\lambda_{j}^{1}, \lambda_{j}^{2}, \cdots, \lambda_{j}^{s}$ be the grey center points of the clustering index $g_{j}$ of the object $O_{i}$, and the range of value allowed for $x_{j}$ is $\left[a_{j}^{1}, a_{j}^{s+1}\right]$, thus we can get center points $\lambda_{j}^{0}, \lambda_{j}^{s+1}$ by extending grey cluster in different directions.

Step 2: Let $b_{j}^{k+1}=\frac{\lambda_{j}^{k}+\lambda_{j}^{k+1}}{2}, k=1,2, \cdots, s$, the method of determining grey interval may have the following cases:
If $\lambda_{j}^{k}=\frac{b_{j}^{k}+b_{j}^{k+1}}{2}$, then we say that $\left[b_{j}^{k}, b_{j}^{k+1}\right)$ is the grey interval of the grey cluster $k$;

If $\lambda_{j}^{k} \neq \frac{b_{j}^{k}+b_{j}^{k+1}}{2}, \quad$ let $\Delta_{k}=\max \left\{\lambda_{j}^{k}-b_{j}^{k}, b_{j}^{k+1}-\lambda_{j}^{k}\right\}$,

then we say that $\left[c_{j}^{k}, c_{j}^{k+1}\right)=\left[\lambda_{j}^{k}-\Delta_{k}, \lambda_{j}^{k}+\Delta_{k}\right)$ is the grey interval of the grey cluster $k$, thus we can make an assumption that $c_{j}^{1}=\min \left\{a_{j}^{1}, b_{j}^{1}, c_{j}^{1}\right\}$ and $c_{j}^{s+1}=\max \left\{a_{j}^{s+1}, b_{j}^{s+1}, c_{j}^{s+1}\right\}$.

Let $\left[c_{j}^{k}, c_{j}^{k+1}\right)$ be the grey interval of the grey cluster $k$, connecting points $\left(c_{j}^{k}, 0\right),\left(\lambda_{j}^{k}, 1\right)$ and $\left(c_{j}^{k+1}, 0\right)$, then we can define the triangular whitenization weight function of the clustering index $g_{j}$ belonging to the grey cluster $k$ is $f_{j}^{k}(\cdot), j=1,2, \cdots, m, k=1,2, \cdots, s$.

For an observation value $x_{j}$ of the clustering index $g_{j}$, $f_{j}^{k}(\cdot), j=1,2, \cdots, m, k=1,2, \cdots, s$ can be defined as:

$$
f_{j}^{k}\left(x_{j}\right)=\left\{\begin{array}{l}
0, \quad x_{j} \notin\left[c_{j}^{k}, c_{j}^{k+1}\right) \\
\frac{x_{j}-c_{j}^{k}}{\lambda_{j}^{k}-c_{j}^{k}}, \quad x_{j} \in\left[c_{j}^{k}, \lambda_{j}^{k}\right) \\
\frac{c_{j}^{k+1}-x_{j}}{c_{j}^{k+1}-\lambda_{j}^{k}}, \quad x_{j} \in\left[\lambda_{j}^{k}, c_{j}^{k+1}\right)
\end{array}\right.
$$

In a similar way, for any $x_{j} \in\left[b_{j}^{k}, b_{j}^{k+1}\right)$, we could define the triangular whitenization weight function $f_{j}^{k}(\cdot)$ of the clustering index $g_{j}$ belonging to the grey cluster $k$.

$$
\text { If }\left[c_{j}^{k-1}, c_{j}^{k}\right) \cap\left[b_{j}^{k}, b_{j}^{k+1}\right) \neq \varnothing \text {, there exist } j_{o} \in\{1,2, \cdots, m\}
$$
such that $x_{j_{0}} \in\left[c_{j}^{k-1}, c_{j}^{k}\right) \cap\left[b_{j}^{k}, b_{j}^{k+1}\right)$. we will choose $f_{j_{0}}^{k^{\prime}}\left(x_{i j_{0}}\right)=\max \left\{f_{j_{0}}^{k-1}\left(x_{j_{0}}\right), f_{j_{0}}^{k}\left(x_{j_{0}}\right)\right\}$. It holds that $f_{j}^{k^{\prime}}\left(x_{j}\right)$ is the triangular whitenization weight function of the clustering index $g_{j}$ belonging to the grey cluster $k^{\prime}$. If $\left[c_{j}^{k-1}, c_{j}^{k}\right) \cap\left[b_{j}^{k}, b_{j}^{k+1}\right)=\varnothing$, then we can calculate $f_{j}^{k}\left(x_{j}\right)$ by Eq. (1) (see Fig. 1).

Step 3: The integrated clustering coefficients of the object $O_{i}$ belonging to the grey cluster $k$ can be given by:

$\sigma^{k}=\sum_{j=1}^{m} f_{j}^{k}\left(x_{j}\right) \eta_{j}$

where $f_{j}^{k}\left(x_{j}\right)$ is the triangular whitenization weight function of the clustering index $g_{j}$ belonging to the grey cluster $k$, $\eta_{j}$ is the weight of clustering index $g_{j}$ in comprehensive 


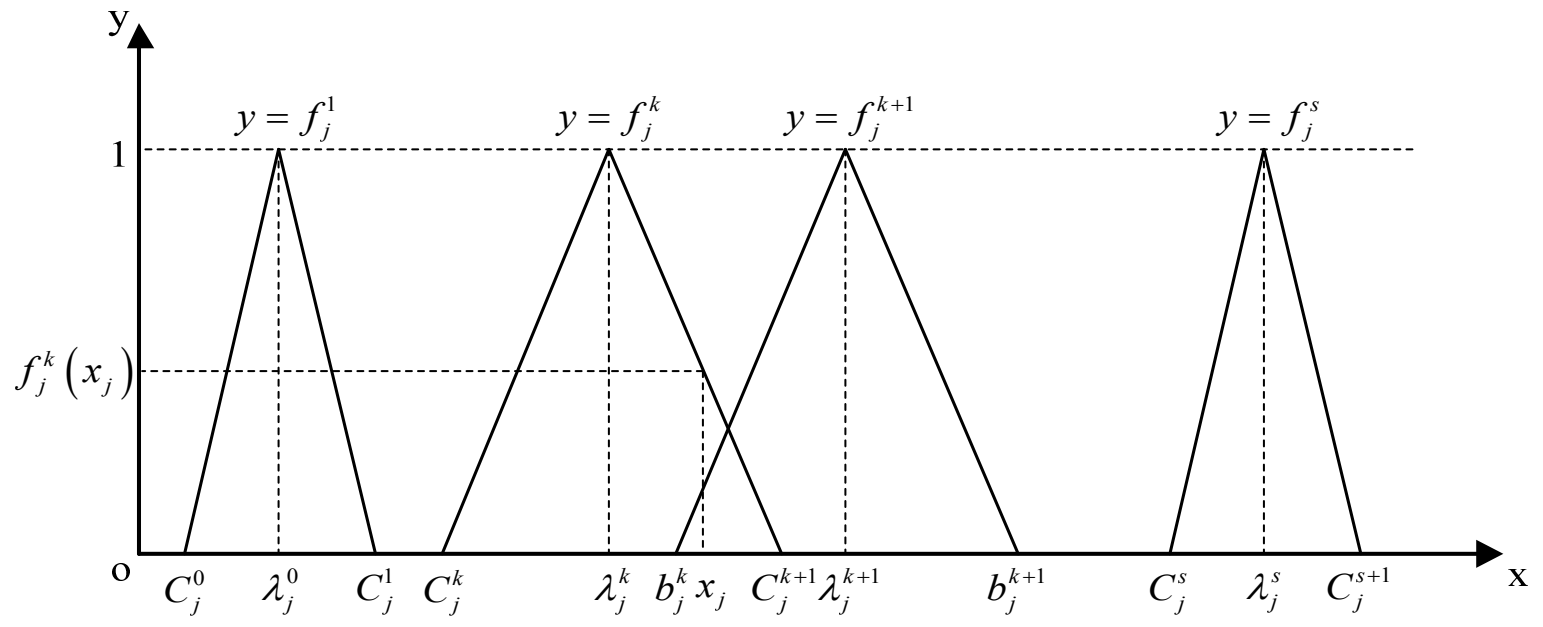

Fig. (1). A sketch of the compact-center-point triangular whitenization weight function.

clustering, and determined by the method of triangular fuzzy number [19].

Step 4: If $\max _{1 \leq k \leq s}\left\{\sigma^{k}\right\}=\sigma^{k^{*}}$, we say that the object $O_{i}$ belongs to the grey cluster $k^{*}$. It means that we can choose the maximal element of a grey clustering coefficient as the clustering result. When more than one objects belong to the grey cluster $k^{*}$, we can sort these objects according to the size of its integrated clustering coefficients, then determine seating arrangement or quality of each object belonging to the grey cluster $k^{*}$.

\section{COMPARATIVE ANALYSIS}

\subsection{The Crossing Properties of Grey Cluster}

From the aspect of the crossing properties of a grey cluster, CTWF is superior to ETWF [8, 17].

Theorem 3.1 [8, 17] There exist more than two multiplecrosses of grey cluster for ETWF.

Theorem 3.2 [8, 17] There exist no multiple-crosses of grey cluster for CTWF.

Note: In fact, according to the proof procedure of Theorem 3.1, we have at least three multiple-crosses of grey cluster for ETWF. According to the proof of Theorem 3.2, we have two multiple-crosses of grey cluster for CTWF. For CTWF, the cross-interval between grey cluster $k-1$ and grey cluster $k$ is $D=\left[\lambda_{k-2}, \lambda_{k}\right) \cap\left[\lambda_{k-1}, \lambda_{k+1}\right)=\left[\lambda_{k-1}, \lambda_{k}\right)$.

Therefore, Theorem 3.2 can be improved as follows.

Theorem 3.3 There exist two multiple-crosses of grey cluster for CCTWF.

Theorem 3.4 There exist two multiple-crosses of grey cluster for CCTWF at most.

Proof. Let $x_{j}$ be an observation value of an object $O_{i}$ for clustering index $g_{j}$. According to the principle of the construction of CCTWF, there exist three kinds of cases, for the grey interval of grey cluster $k-1, k$ and $k+1$.

$$
\begin{aligned}
& {\left[b_{j}^{k-1}, b_{j}^{k}\right),\left[b_{j}^{k}, b_{j}^{k+1}\right),\left[b_{j}^{k+1}, b_{j}^{k+2}\right) \text { or }} \\
& {\left[b_{j}^{k-1}, b_{j}^{k}\right),\left[b_{j}^{k}, b_{j}^{k+1}\right),\left[c_{j}^{k+1}, c_{j}^{k+2}\right) \text { or }} \\
& {\left[c_{j}^{k-1}, c_{j}^{k}\right),\left[c_{j}^{k}, c_{j}^{k+1}\right),\left[c_{j}^{k+1}, c_{j}^{k+2}\right) \text { or }} \\
& {\left[c_{j}^{k-1}, c_{j}^{k}\right),\left[c_{j}^{k}, c_{j}^{k+1}\right),\left[b_{j}^{k+1}, b_{j}^{k+2}\right) . \text { Clearly, there exist }}
\end{aligned}
$$
cross between grey cluster $k$ and grey cluster $k+1$ at most.

$\left[b_{j}^{k-1}, b_{j}^{k}\right),\left[c_{j}^{k}, c_{j}^{k+1}\right),\left[b_{j}^{k+1}, b_{j}^{k+2}\right)$. Since $b_{j}^{k}<\lambda_{k}<b_{j}^{k+1}$, we have $\left[b_{j}^{k-1}, b_{j}^{k}\right) \cap\left[b_{j}^{k+1}, b_{j}^{k+2}\right)=\varnothing$. Hence, there exist cross phenomenon between grey cluster $k-1$ and grey cluster $k$ or cross phenomenon between grey cluster $k$ and grey cluster $k+1$ at most.

$\left[c_{j}^{k-1}, c_{j}^{k}\right),\left[b_{j}^{k}, b_{j}^{k+1}\right),\left[c_{j}^{k+1}, c_{j}^{k+2}\right)$, which is proved similar to the case (2).

Hence, there exist two multiple-crosses of grey cluster for CCTWF at most.

Theorem 3.1, Theorem 3.3 and Theorem 3.4 imply the following results: there exist two multiple-crosses of grey cluster for CCTWF at most, compared with three multiplecrosses of grey cluster for ETWF at least and two multiplecrosses of grey cluster for CTWF. Hence, CCTWF precedes ETWF and CTWF from the aspect of the crossing properties of grey cluster.

\subsection{Clustering Coefficients}

The three kinds of triangular whitenization weight functions describe the degree of an object belonging to a grey cluster in different angles, and whitenization weight function is the key point to determine the integrated clustering coefficients. The grey clustering evaluation model based on ETWF does not satisfy the normative, while the grey clustering evaluation model based on CTWF meets normative (See Theorem 3.5 and Theorem 3.6).

Theorem 3.5 [8, 17] For the grey clustering evaluation model based on ETWF, let $x_{j}$ be an observation value of the 
clustering index $g_{j}$, and $x_{j} \in\left[\lambda_{k-1}, \lambda_{k}\right]$, it holds that $f_{j}^{1}\left(x_{j}\right)+f_{j}^{2}\left(x_{j}\right)+\cdots+f_{j}^{s}\left(x_{j}\right) \neq 1$.

Theorem $3.6[8,17]$ For the grey clustering evaluation model based on CTWF, let $x_{j}$ be an observation value of the clustering index $g_{j}$, and $x_{j} \in\left[\lambda_{k-1}, \lambda_{k}\right]$, it holds that $f_{j}^{1}\left(x_{j}\right)+f_{j}^{2}\left(x_{j}\right)+\cdots+f_{j}^{s}\left(x_{j}\right)=1$.

Note: In Theorem 3.6, the grey clustering evaluation model based on CTWF does not satisfy normative. In fact, if $x \in\left[\lambda_{0}, \lambda_{1}\right)$, then we have

$f_{j}^{1}(x)+f_{j}^{2}(x)+\cdots+f_{j}^{s}(x)=f_{j}^{1}(x)=\frac{x-\lambda_{0}}{\lambda_{1}-\lambda_{0}}<\frac{\lambda_{1}-\lambda_{0}}{\lambda_{1}-\lambda_{0}}=1$.

Therefore, Theorem 3.6 can be improved as follows.

Theorem 3.7 For the grey clustering evaluation model based on CTWF, let $x_{j}$ be an observation value of the clustering index $g_{j}$. If $x_{j} \in\left[\lambda_{k-1}, \lambda_{k}\right], k=2,3, \ldots, s$, then we have $f_{j}^{1}\left(x_{j}\right)+f_{j}^{2}\left(x_{j}\right)+\cdots+f_{j}^{s}\left(x_{j}\right)=1$; If $x_{j} \in\left[\lambda_{0}, \lambda_{1}\right) \cup\left[\lambda_{s}, \lambda_{s+1}\right)$, then we have $f_{j}^{1}\left(x_{j}\right)+f_{j}^{2}\left(x_{j}\right)+\cdots+f_{j}^{s}\left(x_{j}\right)<1$.

Proof If $x_{j} \in\left[\lambda_{k-1}, \lambda_{k}\right], k=2,3, \ldots, s, \quad$ we have $f_{j}^{k-1}\left(x_{j}\right)=\frac{\lambda_{k}-x_{j}}{\lambda_{k}-\lambda_{k-1}}, f_{j}^{k}\left(x_{j}\right)=\frac{x_{j}-\lambda_{k-1}}{\lambda_{k}-\lambda_{k-1}}$, Then $f_{j}^{1}\left(x_{j}\right)+f_{j}^{2}\left(x_{j}\right)+\cdots+f_{j}^{s}\left(x_{j}\right)=f_{j}^{k-1}\left(x_{j}\right)+$ $f_{j}^{k}\left(x_{j}\right)=\frac{\lambda_{k}-x_{j}}{\lambda_{k}-\lambda_{k-1}}+\frac{x_{j}-\lambda_{k-1}}{\lambda_{k}-\lambda_{k-1}}=1$

$$
\text { If } x_{j} \in\left[\lambda_{0}, \lambda_{1}\right) \text {, we have } \begin{array}{r}
f_{j}^{1}\left(x_{j}\right)+f_{j}^{2}\left(x_{j}\right)+\cdots+f_{j}^{s}\left(x_{j}\right)= \\
f_{j}^{1}\left(x_{j}\right)=\frac{x_{j}-\lambda_{0}}{\lambda_{1}-\lambda_{0}}<\frac{\lambda_{1}-\lambda_{0}}{\lambda_{1}-\lambda_{0}}=1 \\
f_{j}^{1}\left(x_{j}\right)+f_{j}^{2}\left(x_{j}\right)+\cdots+f_{j}^{s}\left(x_{j}\right)=
\end{array} .
$$$$
\text { If } x_{j} \in\left[\lambda_{s}, \lambda_{s+1}\right) \text {, we have } f_{j}^{s}\left(x_{j}\right)=\frac{x_{j}-\lambda_{s}}{\lambda_{s+1}-\lambda_{s}}<\frac{\lambda_{s+1}-\lambda_{s}}{\lambda_{s+1}-\lambda_{s}}=1
$$

At this time, we say that the grey clustering evaluation model based on CTWF meets weak normative.

Theorem 3.8 For the grey clustering evaluation model based on CCTWF, let $x_{j}$ be an observation value of the clustering index $g_{j}$, it holds that

$f_{j}^{1}\left(x_{j}\right)+f_{j}^{2}\left(x_{j}\right)+\cdots+f_{j}^{s}\left(x_{j}\right) \leq 1$, and

$f_{j}^{1}\left(x_{j}\right)+f_{j}^{2}\left(x_{j}\right)+\cdots+f_{j}^{s}\left(x_{j}\right)=1$ if and only if

$x_{j} \in\left\{\lambda_{1}, \lambda_{2}, \cdots, \lambda_{s}\right\}$.

Proof (1) let $x_{j}$ be an observation value of the clustering index $g_{j}$, by the principle of the construction of CCTWF, we have $0 \leq f_{j}^{k}\left(x_{j}\right) \leq 1$, and thus $f_{j}^{1}\left(x_{j}\right)+f_{j}^{2}\left(x_{j}\right)+\cdots+f_{j}^{s}\left(x_{j}\right)=f_{j}^{k}\left(x_{j}\right) \leq 1$.

(2) Necessity. For any $x_{j} \in\left\{\lambda_{1}, \lambda_{2}, \cdots, \lambda_{s}\right\}$, take $x_{j}=\lambda_{k}, \forall k \in\{1,2, \cdots, s\}$, it holds that $f_{j}^{k}\left(\lambda_{k}\right)=\frac{b_{k+1}-\lambda_{k}}{b_{k+1}-\lambda_{k}}=1$ by the principle of the construction of CCTWF, thus $f_{j}^{1}\left(x_{j}\right)+f_{j}^{2}\left(x_{j}\right)+\cdots+f_{j}^{s}\left(x_{j}\right)=f_{j}^{k}\left(x_{j}\right)=1$.

Sufficiency. Let $x_{j}$ be an observation value of the clustering index $g_{j}$, we may assume that

$x_{j} \in\left[b_{k-1}, b_{k}\right), k=1,2, \cdots, s+1$, so

$f_{j}^{1}\left(x_{j}\right)+f_{j}^{2}\left(x_{j}\right)+\cdots+f_{j}^{s}\left(x_{j}\right)=f_{j}^{k}\left(x_{j}\right)=1$. It is obvious that $x_{j}=\lambda_{k}, \forall k \in\{1,2, \cdots, s\}$ by the principle of the construction of CCTWF. Hence, the proof is complete.

Consequently, throughout the analysis process above, the ETWF dissatisfies the normative and CTWF meets weak normative and CCTWF meets partially normative. But the new function simplifies the redundant calculation of cross function, and is uncomplicated to be operated, with no need for calculating a triangular whitenization weight function twice, and we will give an illustrative example to verify the desired results (See the values of $f_{j}^{k}(\cdot)$ in Tables 4 and 7).

\subsection{Rules for Grey Clustering Interval}

For ETWF, there is no procedural way to choose the endpoints $a_{0}, a_{1}, a_{2}, \cdots, a_{s}, a_{s+1}, a_{s+2}$ of the triangular whitenization weight function, which implies that the division method of grey cluster lacks adequate scientific basis. For CTWF, the center-point of the grey cluster is $\lambda_{k}$ which mostly belongs to grey cluster $k$, and we are prone to obtain triangular whitenization weight function of the grey cluster based on the center-points $\lambda_{0}, \lambda_{1}, \lambda_{2}, \cdots, \lambda_{s}, \lambda_{s+1}[8$, 17].

Actually, according to our habits of mind, the grasp and judgment of center-point of grey cluster are far more accurate than the grey interval, for this reason CTWF is superior to ETWF from the aspect of the rules for grey clustering interval. The rules for grey cluster interval of CTWF lack certain scientific ideals and need improvement.

We still make the evaluation for the construction of universities [8, 17]. By the evaluation process of this example, we have the following results. In the process of the application of the clustering evaluation method based on CTWF, Liu and Xie divided the interval of performance appraisal of discipline construction into four grey clusters: "excellent type", "good type", "general type" and "poor type" in accordance with appraisal requirements, and determined the center-points $\lambda_{1}=90, \lambda_{2}=80, \lambda_{3}=70, \lambda_{4}=50$, then they took $[79,90],[50,80]$ as the representation of grey clusters "good type" and "general type" [17]. For the interval of grey cluster, "good type" was determined by the centerpoint of grey cluster "excellent type" and grey cluster 
"general type", and the interval of grey cluster "general type" was determined by the center-point of grey cluster "good type" and grey cluster "poor type". In this way the interval length will be enlarged of grey cluster "good type" and grey cluster "general type" in all possible ways. Therefore, the result of evaluation based on the CTWF is unreliable.

By the principle of the construction of CCTWF, we get the divided interval of performance appraisal of discipline construction $\quad[40,60],[60,80],[75,85][80,100]$, which represents the grey clusters "excellent type", "good type", "general type" and "poor type" respectively. These intervals of grey cluster could be more appropriate to the connotation of the center-points and correspond to our habits of mind.

To sum up, the rules for grey clustering interval of CCTWF are more reasonable. In order to verify the correctness of the inference above, we will compare and analyze the clustering performance of the grey clustering evaluation method based on the three kinds of triangular whitenization weight functions, with the example of the comprehensive evaluation of a basin initial water rights allocation scheme. Since the grey clustering evaluation method based on CTWF precedes the grey clustering evaluation method based on ETWF, this paper just applies the grey clustering evaluation method based on CCTWF and the grey clustering evaluation method based on CTWF in the comprehensive evaluation of a basin initial water rights allocation scheme to compare and study the correctness of the above inference.

\section{ANALYSIS OF EXAMPLE}

In recent decades, along with the serious scarcity of water resources, much attention has been focused on water rights allocation systems for solving the water conflicts among different regions in China [20-22]. Under the situation of water scarcity, to build a water rights institution can improve water allocation efficiency among various water using sectors or regions, because it will stimulate water user to establish internal incentive and constraint mechanism of energy saving and emission reduction [23, 24]. An initial allocation of water rights to determine annual water use caps for different users in a reasonable and transparent way underpins better water resources management [25]. The quality of a basin initial water rights allocation scheme directly affects the efficiency of water resources utilization. Hence, it is necessary to evaluate the scheme by an effective method.

Based on the connotation and character of the compound system optimization of a basin initial water rights allocation $[22,25,26]$, as well as the available research results of comprehensive evaluation index system of an initial water rights allocation scheme, we establish the comprehensive evaluation index system of a basin initial water rights allocation scheme on the basis of the investigation and extensive collection of the basin data, and the basin research and interview work, and the suggestion by the river basin administrative agencies and experts in the field of the water environment and water resources, with methods of literature reading, frequency analysis, attribute reduction algorithm, and results reference. As shown in Table $\mathbf{1 .}$

Dalinghe River is the largest single flow in the western of Liaoning province in China. The length of the trunk stream is about $435 \mathrm{~km}$ and the basin area is about 23837 $\mathrm{km}^{2}$. The river stretches across the provinces of Liaoning, Inner Mongolia and Hebei. Its basin area in Liaoning is $20285 \mathrm{~km}^{2}$, which accounts for $85.1 \%$ of the whole. In spite of the shortage and conflicts of water resources, the frame work, such as the comprehensive scheme of social and economic development of this basin, and the comprehensive scheme of water resources, are relatively complete. Hence, this article selects the initial water rights allocation scheme of Dalinghe River as a case to study.

According to the related data given by the available research results [18-20], we get the observation values of the evaluation indexes. Then we figure out the index weights by the method of triangular fuzzy number. Through the triangular fuzzy number to establish judgment matrix based on the importance of evaluation indexes, we obtain the weights of the evaluation indexes by using the third index of Yager to sort the complementary judgment matrix of

Table 1. The Comprehensive Evaluation Index System of an Initial Water Rights Allocation Scheme

\begin{tabular}{|c|c|c|}
\hline Object Layer & Criteria Layer & Index Layer \\
\hline \multirow{10}{*}{$\begin{array}{l}\text { The Comprehensive Evaluation of an Initial Water } \\
\text { Rights Allocation Scheme }\end{array}$} & \multirow{2}{*}{ Society $x_{1}$} & Regional satisfaction of water allocation $x_{11}$ \\
\hline & & Per-capita water allocation $x_{12}$ \\
\hline & \multirow{3}{*}{ Economic $x_{2}$} & Water consumption per ten thousand yuan of agricultural output $x_{21}$ \\
\hline & & Water consumption per ten thousand yuan of industrial output $x_{22}$ \\
\hline & & Water consumption per ten thousand yuan of tertiary industry $x_{23}$ \\
\hline & \multirow{2}{*}{ Ecology $x_{3}$} & Water with green unit $x_{31}$ \\
\hline & & Satisfaction of water with ecological environment $x_{32}$ \\
\hline & \multirow{3}{*}{ Efficiency $x_{4}$} & Utilization coefficient of agricultural water $x_{41}$ \\
\hline & & Utilization coefficient of industrial water $x_{42}$ \\
\hline & & Utilization coefficient of tertiary industry water $x_{43}$ \\
\hline
\end{tabular}


Table 2. Weights of Evaluation Indexes by the Method of Triangular Fuzzy Number

\begin{tabular}{|c|c|c|c|c|c|c|c|c|c|c|c|}
\hline Criteria & \multicolumn{2}{|c|}{ Society $\boldsymbol{x}_{\mathbf{1}}$ (Weight 0.192) } & \multicolumn{3}{c|}{ Economic $\boldsymbol{x}_{\mathbf{2}}$ (Weight 0.326) } & \multicolumn{2}{c|}{ Ecology $\boldsymbol{x}_{3}$ (Weight 0.239) } & \multicolumn{2}{c|}{ Efficiency $\boldsymbol{x}_{4}$ (Weight 0.243) } \\
\hline \hline Index & $x_{11}$ & $x_{12}$ & $x_{21}$ & $x_{22}$ & $x_{23}$ & $x_{31}$ & $x_{32}$ & $x_{41}$ & $x_{42}$ & $x_{43}$ \\
\hline Observation value & 0.889 & 34.176 & 0.096 & 0.908 & 0.996 & 0.030 & 0.980 & 0.621 & 0.930 & 0.869 \\
\hline Weight & 0.127 & 0.085 & 0.105 & 0.132 & 0.084 & 0.119 & 0.131 & 0.073 & 0.092 & 0.052 \\
\hline
\end{tabular}

triangular fuzzy number. As shown in Table 2.

(2) According to the evaluation requirements, we divide the evaluation of an initial water rights allocation scheme of Dalinghe River into four grey clusters: "excellent type", "good type", "general type" and "poor type".

1) By the grey clustering evaluation method based on CTWF, the initial water rights allocation scheme of Dalinghe River is evaluated comprehensively.

Step1: Determine the grey interval of grey cluster. Combining with the suggestion of the river basin administrative agencies and experts in the field of the water environment and water resources, the center-points of the grey cluster are determined, and then we can obtain the grey interval of grey cluster based on the center-points. As shown in Table 3.

Step 2: Calculate the triangular whitenization weight function of the index values. By the principle of the construction of CTWF, we can calculate the triangular whitenization weight function $f_{j}^{k}\left(x_{i j}\right), k=1,2,3,4$. For the observation value $x_{11}$ of the clustering index $x_{1}$, $f_{1}^{k}\left(x_{11}\right), k=1,2,3,4$ can be defined as:

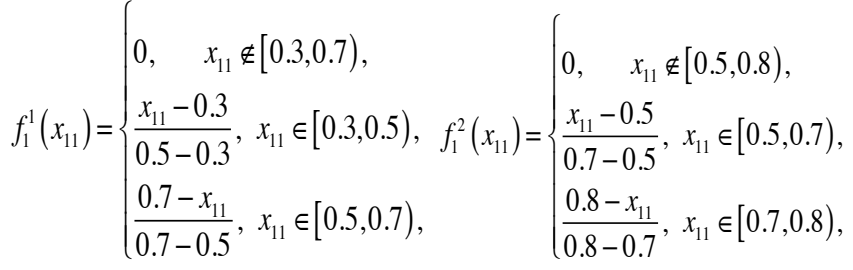$$
f_{1}^{3}\left(x_{11}\right)=\left\{\begin{array}{l}
0, \quad x_{11} \notin[0.7,0.9), \\
\frac{x_{11}-0.7}{0.8-0.7}, x_{11} \in[0.7,0.8), \quad f_{1}^{4}\left(x_{11}\right)=\left\{\begin{array}{l}
0, \quad x_{11} \notin[0.8,1.0), \\
\frac{0.9-x_{11}}{0.9-0.8}, x_{11} \in[0.8 \\
0.9-0.8
\end{array}, x_{11} \in[0.8,0.9),\right. \\
\frac{1.0-x_{11}}{1.0-0.9}, x_{11} \in[0.9,1.0),
\end{array}\right.
$$

For $x_{11}=0.889$, we have

$$
\left(f_{1}^{1}\left(x_{11}\right), f_{1}^{2}\left(x_{11}\right), f_{1}^{3}\left(x_{11}\right), f_{1}^{4}\left(x_{11}\right)\right)=(0,0,0.11,0.89) \text {. }
$$

Then, the others can be calculated similarly to the observation value $x_{11}$. As shown in Table 4 .

Step 3: Calculate the integrated clustering coefficients. By the Eq. (4) of the integrated clustering coefficient of CTWF [17], we can calculate the indexes of criteria layer along with the integrated clustering coefficients of an initial

Table 3. The Grey Interval of Grey Cluster Based on the Center-Points

\begin{tabular}{|c|c|c|c|c|}
\hline Index & Poor Type & General Type & Good Type & Excellent Type \\
\hline \hline$x_{11}$ & $0.3 \leq x_{11}<0.7$ & $0.5 \leq x_{11}<0.8$ & $0.7 \leq x_{11}<0.9$ & $0.8 \leq x_{11}<1.0$ \\
\hline$x_{12}$ & $5 \leq x_{12}<20$ & $10 \leq x_{12}<30$ & $20 \leq x_{12}<40$ & $0.6 \leq x_{21}<1.0$ \\
\hline$x_{21}$ & $0 \leq x_{21}<0.4$ & $0.2 \leq x_{21}<0.6$ & $0.4 \leq x_{21}<0.8$ & $0.85 \leq x_{22}<1.0$ \\
\hline$x_{22}$ & $0.55 \leq x_{22}<0.75$ & $0.65 \leq x_{22}<0.85$ & $0.75 \leq x_{22}<0.95$ & $0.9 \leq x_{23}<1.0$ \\
\hline$x_{23}$ & $0.75 \leq x_{23}<0.85$ & $0.8 \leq x_{23}<0.9$ & $0.85 \leq x_{23}<0.95$ & $0.05 \leq x_{31}<0.08$ \\
\hline$x_{31}$ & $0.005 \leq x_{31}<0.035$ & $0.02 \leq x_{31}<0.05$ & $0.035 \leq x_{31}<0.065$ & $0.8 \leq x_{32}<1.0$ \\
\hline$x_{32}$ & $0.5 \leq x_{32}<0.7$ & $0.6 \leq x_{32}<0.8$ & $0.7 \leq x_{32}<0.9$ & $0.8 \leq x_{41}<1.0$ \\
\hline$x_{41}$ & $0.3 \leq x_{41}<0.7$ & $0.5 \leq x_{41}<0.8$ & $0.7 \leq x_{41}<0.9$ & $0.8 \leq x_{42}<1.0$ \\
\hline$x_{42}$ & $0.5 \leq x_{42}<0.7$ & $0.6 \leq x_{42}<0.8$ & $0.7 \leq x_{42}<0.9$ & $0.8 \leq x_{43}<1.0$ \\
\hline$x_{43}$ & $0.3 \leq x_{43}<0.7$ & $0.5 \leq x_{43}<0.8$ & $0.7 \leq x_{43}<0.9$ & 0 \\
\hline
\end{tabular}


Table 4. The Triangular Whitenization Weight Function of the Index Values

\begin{tabular}{|c|c|c|c|c|c|c|c|c|c|c|}
\hline Code & $\boldsymbol{x}_{\mathbf{1 1}}$ & $\boldsymbol{x}_{\mathbf{1 2}}$ & $\boldsymbol{x}_{\mathbf{2 1}}$ & $\boldsymbol{x}_{\mathbf{2 2}}$ & $\boldsymbol{x}_{\mathbf{2 3}}$ & $\boldsymbol{x}_{\mathbf{3 1}}$ & $\boldsymbol{x}_{\mathbf{3 2}}$ & $\boldsymbol{x}_{\mathbf{4 1}}$ & $\boldsymbol{x}_{\mathbf{4 2}}$ & $\boldsymbol{x}_{\mathbf{4 3}}$ \\
\hline \hline$f_{j}^{1}\left(x_{i j}\right)$ & 0 & 0 & 0.48 & 0 & 0 & 0.333 & 0 & 0.395 & 0 \\
\hline$f_{j}^{2}\left(x_{i j}\right)$ & 0 & 0 & 0 & 0 & 0 & 0.667 & 0 & 0.605 & 0 \\
\hline$f_{j}^{3}\left(x_{i j}\right)$ & 0.110 & 0.582 & 0 & 0.420 & 0 & 0 & 0 & 0 & 0 \\
\hline$f_{j}^{4}\left(x_{i j}\right)$ & 0.890 & 0.418 & 0 & 0.580 & 0.080 & 0 & 0.200 & 0 & 0.310 \\
\hline
\end{tabular}

water rights allocation scheme of Dalinghe River, which are shown in Table $\mathbf{5}$.

Step 4: According to $\max _{1 \leq k \leq 4}\left\{\sigma^{k}\right\}=\sigma^{4}=0.086$, we can see that the comprehensive evaluation result of an initial water rights allocation scheme of Dalinghe River belongs to the grey cluster of "excellent type".

2) By the grey clustering evaluation method based on CCTWF, the initial water rights allocation scheme of Dalinghe River is evaluated comprehensively.
Step1: Determine the grey interval of grey cluster. Combining with the suggestion of the river basin administrative agencies and experts in the field of the water environment and water resources, and the center-points of the grey cluster, the compact-center-points of the grey cluster are determined, and then we can obtain the grey interval of grey cluster based on the compact-center-points. As it is shown in Table 6.

Step 2: Calculate the triangular whitenization weight function of the index values. By the Eq.(1), we can calculate

Table 5. The Integrated Clustering Coefficients of an Initial Water Rights Allocation Scheme

\begin{tabular}{|c|c|c|c|c|c|}
\hline Grey Cluster & $\boldsymbol{x}_{\mathbf{1}}$ & $\boldsymbol{x}_{\mathbf{2}}$ & $\boldsymbol{x}_{\mathbf{3}}$ & $\boldsymbol{x}_{\mathbf{4}}$ & 0.029 \\
\hline \hline Poor type & 0 & 0.050 & 0.040 & 0.044 & 0.032 \\
\hline General type & 0 & 0 & 0.079 & 0.016 & 0.029 \\
\hline Good type & 0.063 & 0.055 & 0 & 0.100 & 0.086 \\
\hline Excellent type & 0.149 & 0.083 & 0.026 & \\
\hline
\end{tabular}

Table 6. The Grey Interval of Grey Cluster Based on the Compact-Center-Points

\begin{tabular}{|c|c|c|c|c|}
\hline Index & Poor Type & General Type & Good Type & Excellent Type \\
\hline \hline$x_{11}$ & $0.3 \leq x_{11}<0.7$ & $0.6 \leq x_{11}<0.8$ & $0.75 \leq x_{11}<0.85$ & $0.8 \leq x_{11}<1.0$ \\
\hline$x_{12}$ & $5 \leq x_{12}<15$ & $15 \leq x_{12}<25$ & $25 \leq x_{12}<35$ & $0.6 \leq x_{21}<45$ \\
\hline$x_{21}$ & $0 \leq x_{21}<0.4$ & $0.3 \leq x_{21}<0.5$ & $0.5 \leq x_{21}<0.7$ & $0.9 \leq x_{22}<1.0$ \\
\hline$x_{22}$ & $0.55 \leq x_{22}<0.75$ & $0.7 \leq x_{22}<0.8$ & $0.8 \leq x_{22}<0.9$ & $0.90 \leq x_{23}<1.0$ \\
\hline$x_{23}$ & $0.75 \leq x_{23}<0.85$ & $0.825 \leq x_{23}<0.875$ & $0.875 \leq x_{23}<0.925$ & $0.05 \leq x_{31}<0.08$ \\
\hline$x_{31}$ & $0.005 \leq x_{31}<0.035$ & $0.028 \leq x_{31}<0.043$ & $0.043 \leq x_{31}<0.058$ & $0.8 \leq x_{32}<1.0$ \\
\hline$x_{32}$ & $0.5 \leq x_{32}<0.7$ & $0.65 \leq x_{32}<0.75$ & $0.75 \leq x_{32}<0.85$ & $0.8 \leq x_{41}<1.0$ \\
\hline$x_{41}$ & $0.3 \leq x_{41}<0.7$ & $0.6 \leq x_{41}<0.8$ & $0.75 \leq x_{41}<0.85$ & $0.8 \leq x_{42}<1.0$ \\
\hline$x_{42}$ & $0.5 \leq x_{42}<0.7$ & $0.65 \leq x_{42}<0.75$ & $0.75 \leq x_{42}<0.85$ & $0.8 \leq x_{43}<1.0$ \\
\hline$x_{43}$ & $0.3 \leq x_{43}<0.7$ & $0.6 \leq x_{43}<0.8$ & $0.75 \leq x_{43}<0.85$ & 0 \\
\hline
\end{tabular}


the triangular whitenization weight function $f_{j}^{k}\left(x_{i j}\right), k=1,2,3,4$. For the observation value $x_{11}$ of the clustering index $x_{1}$, $f_{1}^{k}\left(x_{11}\right), k=1,2,3,4$ can be defined as:

$f_{1}^{1}\left(x_{11}\right)=\left\{\begin{array}{l}0, \quad x_{11} \notin[0.3,0.7) \\ \frac{x_{11}-0.3}{0.5-0.3}, x_{11} \in[0.3,0.5), f_{1}^{2}\left(x_{11}\right)=\left\{\begin{array}{l}0, \quad x_{11} \notin[0.6,0.8) \\ \frac{x_{11}-0.6}{0.7-x_{11}} \\ 0.7-0.6\end{array}, x_{11} \in[0.50 .6,0.7)\right. \\ \frac{0.8-x_{11}}{0.8-0.7}, x_{11} \in[0.7,0.8)\end{array}\right.$

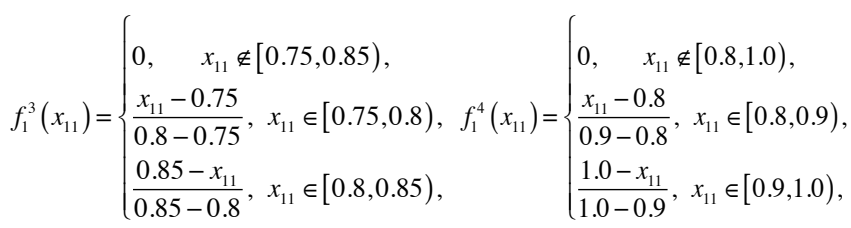

For $x_{11}=0.889$, we have

$\left(f_{1}^{1}\left(x_{11}\right), f_{1}^{2}\left(x_{11}\right), f_{1}^{3}\left(x_{11}\right), f_{1}^{4}\left(x_{11}\right)\right)=(0,0,0,0.89)$. Then,

the others can be calculated similarly to the observation value $x_{11}$. As it is shown in Table 7 .

Step 3: Calculate the integrated clustering coefficients. By the Eq. (2), we can calculate the indexes of criteria layer along with the integrated clustering coefficients of an initial water rights allocation scheme of Dalinghe River, which are shown in Table $\mathbf{8}$.

Step 4: According to $\max _{1 \leq k \leq 4}\left\{\sigma^{k}\right\}=\sigma^{4}=0.060$, we can see that the comprehensive evaluation result of an initial water rights allocation scheme of Dalinghe River belongs to the grey cluster of "excellent type".

\section{3) Analysis of the evaluation results}

According to the related data in Tables $\mathbf{3}$ and $\mathbf{6}$, we can find that there exist two multiple-crosses of grey cluster for CCTWF at most, compared with two multiple-crosses of grey cluster for CTWF.

According to the related data in Table 4, we can find that the sum of clustering coefficients of the indexes belongs to the grey cluster of "excellent type", "good type", "general type" and "poor type" which is not always in unity, which indicates that the grey clustering evaluation model based on CTWF just meets weak normative. Comparing Table $\mathbf{4}$ with Table 7, the calculation of clustering coefficient based on CCTWF simplifies the redundant calculation of cross function, being easy and uncomplicated to be operated.

According to $\max _{1 \leq k \leq 4}\left\{\sigma^{k}\right\}=\sigma^{k^{*}}$, we can see that the comprehensive evaluation result of an initial water rights allocation scheme of Dalinghe River belongs to the grey cluster of "excellent type" based on the related data in Tables $\mathbf{5}$ and $\mathbf{8}$, which is reflected in the aspects of social rationality, economic rationality, ecological rationality and efficiency rationality. Generally, this allocation scheme reflects fairness and efficiency of water allocation among all the regions in the compound system, pays attention to ecological and environmental protection and ensures the reasonability and effectiveness of the allocated water among all the regions, which is beneficial to coordinated development among all the regions. However, the evaluation result differs from the former in the aspect of economic rationality. That is to say, the evaluation result based on CTWF indicates that the scheme belongs to grey cluster of "excellent type", while the same scheme belongs to grey cluster of "poor type" in the light of the grey evaluation result based on CCTWF.

Actually, by means of deliberate discussion for the evaluation results with the experts of administrative agencies

Table 7. The Triangular Whitenization Weight Function of the Index Values

\begin{tabular}{|c|c|c|c|c|c|c|c|c|c|}
\hline Code & $\boldsymbol{x}_{\mathbf{1 1}}$ & $\boldsymbol{x}_{\mathbf{1 2}}$ & $\boldsymbol{x}_{\mathbf{2 1}}$ & $\boldsymbol{x}_{\mathbf{2 2}}$ & $\boldsymbol{x}_{\mathbf{2 3}}$ & $\boldsymbol{x}_{\mathbf{3 1}}$ & $\boldsymbol{x}_{\mathbf{3 2}}$ & $\boldsymbol{x}_{\mathbf{4 1}}$ & $\boldsymbol{x}_{\mathbf{4 2}}$ \\
\hline \hline$f_{j}^{1}\left(x_{i j}\right)$ & 0 & 0 & 0.48 & 0 & 0 & 0 & 0 & 0 & 0 \\
\hline$f_{j}^{1}\left(x_{i j}\right)$ & 0 & 0 & 0 & 0 & 0 & 0.333 & 0 & 0.210 & 0 \\
\hline$f_{j}^{3}\left(x_{i j}\right)$ & 0 & 0.824 & 0 & 0 & 0 & 0 & 0 & 0 & 0 \\
\hline$f_{j}^{4}\left(x_{i j}\right)$ & 0.890 & 0 & 0 & 0.160 & 0.080 & 0 & 0.2 & 0 & 0 \\
\hline
\end{tabular}

Table 8. The Integrated Clustering Coefficients of an Initial Water Rights Allocation Scheme

\begin{tabular}{|c|c|c|c|c|c|}
\hline Grey Cluster & $\boldsymbol{x}_{\mathbf{1}}$ & $\boldsymbol{x}_{\mathbf{2}}$ & $\boldsymbol{x}_{\mathbf{3}}$ & $\boldsymbol{x}_{\mathbf{4}}$ & $\boldsymbol{x}$ \\
\hline \hline Poor type & 0 & 0.050 & 0 & 0 & 0.016 \\
\hline General type & 0 & 0 & 0.036 & 0.014 \\
\hline Good type & 0.070 & 0 & 0 & 0.100 & 0.013 \\
\hline Excellent type & 0.110 & 0.027 & 0.026 & 0.060 \\
\hline
\end{tabular}


of Dalinghe River, we find that the economic rationality of regional distributed water is at a lower level. For instance, the ten thousand yuan per agricultural water consumption of Panjin is $13728.98 \mathrm{~m}^{3}$, compared with $328.70 \mathrm{~m}^{3}$ of Chengde and $278.53 \mathrm{~m}^{3}$ of Chifeng, and technology of water-saving irrigation of Panjin is extremely poor, which indicates that the water-use efficiency of Panjin is poorer than others. Therefore, on one hand, the feasibility and effectiveness of the grey clustering evaluation method based on CCTWF can be verified. That is to say, Panjin should take appropriate measures such as introducing advanced technology to develop water-saving irrigation agriculture and reduce ten thousand yuan output value per agricultural water consumption, for improving the efficiency and benefit of the water-use.

\section{CONCLUSIONS}

The grey clustering evaluation method based on CCTWF is constructed, which is motivated by ideas of the grey clustering evaluation methods based on ETWF and CTWF. The three kinds of triangular whitenization weight functions are compared in terms of the crossing properties of grey cluster, clustering coefficients, rules for grey clustering interval, rules for choosing end-points, clustering performance. The main conclusions are as follows:

(1) In the light of the comparative research on the crossing properties of grey cluster, we can see that CCTWF precedes ETWF and CTWF;

(2) By the comparative research on clustering coefficients, we can find that ETWF dissatisfies the normative, CTWF meets weak normative and CCTWF meets partially normative. But the new function simplifies the redundant calculation of cross function and is uncomplicated to be operated, with no need for calculating a triangular whitenization weight function twice (See the values of $f_{j}^{k}(\cdot)$ in Tables 4 and 7);

(3) Based on the comparative research on rules for grey clustering interval, the division of grey clustering interval of CCTWF further corresponds with the connotation of the central point and conforms to our habits of mind. And it is demonstrated scientifically by the example of evaluation of construction of universities;

(4) The comprehensive evaluation scheme of a basin initial water rights allocation scheme further demonstrates the correctness of the inferences above, and the feasibility and validity of the grey clustering evaluation model based on CCTWF.

Hence, to some extent, the grey clustering evaluation method based on CCTWF precedes the methods based on ETWF and CTWF.

\section{CONFLICT OF INTEREST}

The authors confirm that this article content has no conflict of interest.

\section{ACKNOWLEDGEMENTS}

This work was supported by the National Natural Science Foundation of China (Grant No. 41271537).

\section{REFERENCES}

[1] J. L. Deng, The Base of Grey Theory. Science Press: Beijing, China, 2010

[2] G. W. Wei, "Grey relational analysis method for 2-tuple linguistic multiple attribute group decision making with incomplete weight information", Expert Syst. Appl., vol. 38, pp. 4824-4828, 2011.

[3] J. L. Deng, The Basic Methods of Grey System. Huazhong University of Technology Press: Wuhan, China, 1988.

[4] J. L. Deng, "Introduction to grey system". J. Grey Syst., vol. 1, pp. 1-24, 1989.

[5] J. L. Deng, Grey System Theory. Huazhong University of Science \& Technology Press: Wuhan, China, 2002.

[6] S. F. Liu, and Y. D. Zhu, "Study on triangular model and indexes in synthetic evaluation of regional economy", Trans. Chin. Soc. Agric. Eng.,vol. 9, pp. 8-13, 1993.

[7] S. F. Liu, "On index system and mathematical model for evaluation of scientific and technical strength", Kybenetes, vol. 35, pp. 12561264, 2006.

[8] S. F. Liu, Y. G. Dang, and Z. G. Fang, Grey System Theory and it's Applications. Science Press: Beijing, China, 2010.

[9] C. B. Madhuri, and J. A. Chandulal, "Evaluating web sites using COPRAS-GRA combined with grey clustering", Int. J. Eng. Sci., vol. 2, pp. 5280-5294, 2010.

[10] X. W. Liu, "Agricultural ecological environmental quality assessment of typical county in Yangtze River Delta", Syst. Eng. Theory Pract., vol. 25, pp. 133-138, 2005.

[11] Q. Yang, Y. Li, and L. S. Duan, "Compositive assessment model of venture enterprises investment value based on grey theory", Wuhan Univ. Technol.: Trans. Sci. Eng. Ed., vol. 29, pp. 495-498, 2005.

[12] L. F. Zhou, and S. G. Xu, "Application of grey clustering method in eutrophication assessment of wetland", J. Am. Sci., vol. 2, pp. 54-58, 2006.

[13] Y. Guo, Q. L. Zhou, and J. B. Huang, "The grey evaluation of road traffic safety based on triangular whitening weight function", Chin.Eng. Sci., vol. 8, pp. 87-90, 2006.

[14] J. J. Liu, W. Wang, and L. Cheng, "The grey number evaluation of road net based on trigonometry whitening weight function", Syst. Eng.: Theory Pract., vol. 27, pp. 156-160, 2007.

[15] Z. Q. Yang, H. H. Yi, and Z. Y. Tang, "Operational effect evaluation of self-propelled gun based on triangle whitening function", J. Sichuan Ordnance., vol. 10, pp. 58-60, 2011.

[16] J. F. Zhang, Z. J. Wu, P. F. Feng, and D. W. Yu, "Evaluation systems and methods of enterprise information and application", Expert Syst. Appl., vol. 38, pp. 8938-8948, 2011.

[17] S. F. Liu, and N. M. Xie, "New grey evaluation method based on reformative triangular whitenization weight function", J. Syst. Eng., vol. 38, pp. 8938-8948, 2011.

[18] W. Meng, S. F. Liu, B. Zeng, and N. M. Xie, "Standard triangular whitenization weight function and its application in grey clustering evaluation", J. Grey Syst., vol. 24, pp. 39-48, 2012.

[19] R. Fullér, "On hamacher sum of triangular fuzzy numbers", Fuzzy Set. Syst., vol. 42, pp. 205-212, 1991.

[20] E. Gao, Water Rights System Development in China. China Water and Hydropower Press: Beijing, China, 2006.

[21] Y. P. Chen, F. P. Wu, and D. Wu, "Region-oriented basin initial water rights harmonious allocation model", In: Proceedings International Conference on Management and Service Science, 2009, pp. 29-32. 
[22] H. Wang, L. W. Dang, X. M. Xie, Theory and Practice on Allocation of Initial Water Rights in a Watershed. China Water Resources and Hydropower Press: China, Beijing, 2008.

[23] X. S. Diao, and T. Rao, "Can a water market avert the "doublewhammy" of trade reform and lead to a "win-win" outcome"? J. Environ. Econ. Manag., vol. 131, pp. 735-746, 1999.

[24] M. Jennifer, "Water institutional reforms in Australia", Water Policy, vol. 7, pp: 35-52, 2005.
[25] Z. J. Wang, H. Zheng, and X. F. Wang, "A harmonious water rights allocation model for Shiyang River basin, Gansu Province, China", Water Resour. Dev., vol. 25, pp. 355-371, 2009.

[26] D. Wu, F. P. Wu, and Y. P. Chen, "Principle-subordinate hierarchical multi-objective programming model of initial water rights allocation”, Water Sci. Eng., vol. 2, pp. 105-116, 2009.

Received: March 16, 2013

Revised: April 22, 2013

Accepted: April 22, 2013

(C) Zhang et al.; Licensee Bentham Open.

This is an open access article licensed under the terms of the Creative Commons Attribution Non-Commercial License (http://creativecommons.org/licenses/ by-nc/3.0/) which permits unrestricted, non-commercial use, distribution and reproduction in any medium, provided the work is properly cited. 